\title{
Extraesophageal manifestations of gastroesophageal reflux disease*
}

RICHARD RICACHENEVSKI GURSKI ${ }^{1}$, ANDRÉ RICARDO PEREIRA DA ROSA², ENIO DO VALLE ${ }^{3}$, MARCELO ANTONIO DE BORBA ${ }^{4}$, ANDRÉ ALVES VALIATI ${ }^{4}$

\begin{abstract}
Gastroesophageal reflux disease often presents as heartburn and acid reflux, the so-called "typical" symptoms. However, a subgroup of patients presents a collection of signs and symptoms that are not directly related to esophageal damage. These are known collectively as the extraesophageal manifestations of gastroesophageal reflux disease. Principal among such manifestations are bronchospasm, chronic cough and laryngitis, which are classified as atypical symptoms. These manifestations comprise a heterogeneous group. However, some generalizations can be made regarding all of the subgroups. First, although the correlation between gastroesophageal reflux disease and the extraesophageal manifestations has been well established, a cause-and-effect relationship has yet to be definitively elucidated. In addition, the main proposed pathogenic mechanisms of extraesophageal reflux are direct injury of the extraesophageal tissue (caused by contact with gastric acid) and the esophagobronchial reflex, which is mediated by the vagus nerve. Furthermore, gastroesophageal reflux disease might not be considered in the differential diagnosis of patients presenting only the atypical symptoms. In this article, we review the extraesophageal manifestations of gastroesophageal reflux disease, discussing its epidemiology, pathogenesis, diagnosis and treatment. We focus on the most extensively studied and wellestablished presentations.
\end{abstract}

Keywords: Gastroesophageal reflux/complications; Asthma; Laryngitis; Cough; Fundoplication; Respiration disorders/etiology

\footnotetext{
* Study carried out at the Universidade Federal do Rio Grande do Sul (UFRGS, Federal University of Rio Grande do Sul), Porto Alegre, Rio Grande do Sul; and the Digestive System Institute of Rio Grande do Sul, Porto Alegre, Rio Grande do Sul, Brazil. 1.PhD from the Universidade Federal do Rio Grande do Sul (UFRGS, Federal University of Rio Grande do Sul); Postdoctorate work conducted at the University of Southern California (USC); Professor of the UFRGS Graduate Course in Surgery; Attending physician at the Porto Alegre Hospital de Clínicas, Porto Alegre, Rio Grande do Sul, Brazil

2. PhD in Surgery from the Universidade Federal do Rio Grande do Sul (UFRGS, Federal University of Rio Grande do Sul); Surgeon at the Porto Alegre Hospital de Clínicas, Porto Alegre, Rio Grande do Sul, Brazil

3. PPulmonologist at the Hospital Moinhos de Vento in Porto Alegre, Rio Grande do Sul, Brazil; Fellow do American College of Chest Physicians, Northbrook, Illinois.

4. Student at the Universidade Federal do Rio Grande do Sul (UFRGS, Federal University of Rio Grande do Sul), Porto Alegre, Rio Grande do Sul, Brazil

Correspondence to: Richard Gurski. Rua Schiller, 139 - CEP: 90430-150, Porto Alegre, RS, Brazil.

Phone: 5551 3388-6666. E-mail: rgurski@iadrs.com.br

Submitted: 11 March 2005. Accepted, after review: 7 July 2005.
} 


\section{INTRODUCTION}

It is extremely common that patients with gastroesophageal reflux disease (GERD) experience symptoms, approximately $20 \%$ of adults reporting having heartburn, acid reflux or both at least once a week and approximately $40 \%$ reporting that such symptoms occur at least one a month. ${ }^{(1)}$ If extraesophageal manifestations are taken into consideration, it is believed that the real prevalence of pathological reflux might be underestimated. The denomination 'atypical symptoms' is synonymous with GERD-related sophageal symptoms. These are listed in Chart 1.

It has been shown that GERD is associated with pulmonary symptoms, as well as with lower airway diseases (asthma, chronic cough, bronchitis, aspiration pneumonia and idiopathic pulmonary fibrosis), otorhinolaryngologic signs/symptoms (hoarseness, laryngitis, subglottic stenosis, vocal cord granuloma and laryngeal carcinoma) and other extraesophageal manifestations (noncardiac chest pain, dental erosion, sinusitis, pharyngitis and sleep apnea).

Most patients with extra-esophageal GERD symptoms do not present the typical symptoms. This makes it difficult to diagnose GERD (with atypical symptoms), since, in most of the cases, the subsequent investigation will be based primarily on clinical suspicion.

Patients with extra-esophageal GERD manifestations, when evaluated through upper digestive endoscopy, usually present a low prevalence of esophagitis. The strength of the correlation between erosive esophagitis and pulmonary diseases is shown in Table 1.

In GERD patients with or without classical GERD symptoms, including those with esophagitis, 24-hour esophageal pH monitoring (24-h pHmetry) becomes a useful tool to document pathological reflux. However, this exam cannot be considered the gold standard because of the high rate of falsenegative results $(20 \%$ to $50 \%)$, making it impossible to rule out a diagnosis of GERD. ${ }^{(2)} \mathrm{ln}$ addition, a positive test only confirms the coexistence of pathological gastroesophageal reflux and symptoms, without guaranteeing the existence of a cause-and-effect relationship. Such a relationship can be established only when the extra-esophageal signs or symptoms are resolved or significantly reduced after efficacious antacid clinical treatment or antireflux surgery.

This article reviews the main extra-esophageal manifestations of GERD presented in the literature, discussing the epidemiology, pathogenesis, diagnosis and treatment, as well as focusing on the most prevalent and studied presentations (asthma, chronic cough and laryngitis).

\section{ASTHMA AND GERD}

Asthma is a highly prevalent disease whose incidence has increased in the last decades, affecting $5 \%$ to $10 \%$ of the global population. ${ }^{(3)}$ Pathological gastroesophageal reflux has been found in up to $80 \%$ of adults with asthma. ${ }^{(4)}$ There is mounting epidemiological evidence of an association between GERD and asthma, as well as of a strong correlation between reflux episodes and respiratory symptoms. In addition, some studies have established not only the co-existence, but also the cause-and-effect relationship, establishing GERD as one of the significant causes of asthma in adults.

In accordance with the 111 Brazilian Consensus on Asthma Management, ${ }^{(5)}$ patients with asthma accompanied by another clinical entity (such as GERD), which provokes or exacerbates the asthma symptoms, should be evaluated by a specialist.

Chart 1 - Gastroesophageal reflux disease-related extra-esophageal signs and symptoms

Pulmonary

Asthma, Chronic cough, Recurrent pneumonia, Pneumonitis, Lung abscess, Apnea in children, Sudden death syndrome in children, Cyanosis in children, Bronchopulmonary dysplasia in children, Recurrent croup, Obstructive sleep apnea in adults, ldiopathic pulmonary fibrosis, Chronic obstructive pulmonary disease, Chronic bronchitis

Otorhinolaryngological

Laryngitis, Tonsillitis, Hoarseness, Thoat clearing, Globus, Choking sensation, Contact laryngeal ulcers, Laryngomalacia, Posterior glottic edema and erythema, Laryngeal granuloma, Laryngeal cancer, Pharyngeal cancer, Laryngospasm, Stridor, Subglottic stenosis, Pharyngeal stenosis, Vasomotor rhinitis 


\section{TABLE 1}

Strength of the correlation between erosive esophagitis and pulmonary diseases

\begin{tabular}{lcr}
\hline Pulmonary Disease & Odds Ratio & $95 \% \mathrm{Cl}$ \\
\hline Asthma & 1.51 & $1.43-1.59$ \\
Pulmonary fibrosis & 1.36 & $1.25-1.48$ \\
Atelectasis & 1.31 & $1.23-1.40$ \\
Chronic Bronchitis & 1.28 & $1.22-1.34$ \\
Bronchiectasis & 1.26 & $1.09-1.47$ \\
COPD & 1.22 & $1.16-1.27$ \\
Pneumonia & 1.15 & $1.12-1.18$ \\
\hline
\end{tabular}

$\overline{95 \% \mathrm{Cl}=\text { Confidence lnterval; COPD: chronic obstructive }}$ pulmonary disease

\section{Pathogenesis and diagnosis}

Even though the association between asthma and GERD has been well established, the causeand-effect relationship is still an object of controversy. Physiological alterations in asthmatic patients, such as increased intrathoracic pressure and hemidiaphragm rectification could debilitate the antireflux barrier and consequently predispose to GERD. Some authors ${ }^{(6)}$ have suggested that the prevalence of GERD is higher in patients with chronic obstructive pulmonary disease, indicating that altered respiratory mechanics predisposes to GERD.

Regarding the medication used in the control of asthma, some might favor reflux medications, such as theophylline and adrenergic beta-agonists, because they relax the smooth muscles of the esophagus and stomach. ${ }^{(7-8)}$ However, such medications cause reduced esophageal clearance capacity and delayed gastric emptying, resulting in a proreflux effect, especially in patients with mechanical defects of the lower esophageal sphincter.

Two primary mechanisms have been proposed in the pathogenesis of GERD-related asthma: microaspiration of the refluxed gastric contents and esophagobronchial reflex triggered by the stimulation of vagal receptors in the distal third of the esophagus.

Through the mechanism of microaspiration, the pulmonary symptoms would result from the direct aggression of acids and enzymes present in the reflux gastric contents on the respiratory mucosa, thereby leading to reflex bronchospasm. The results of various studies sustain the idea that this mechanism is implicated in GERD-related asthma. One such study involved intra-esophageal application of hydrochloric acid in patients with asthma. ${ }^{(9)}$ The authors observed reversible increases in airway resistance and bronchial secretion in a significant proportion of the patients studied. They also found that those alterations were inhibited by atropine, indicating that this mechanism is mediated by the vagus nerve. ${ }^{(9)}$

The most commonly used exams for the diagnosis of GERD-induced asthma present less than satisfactory sensitivity and specificity. The 24-h pHmetry, despite identifying and quantifying the pathological acid reflux, presents a high rate of false-negative results. Furthermore, it is an uncomfortable, invasive exam, the results of which are not often reproducible. Therefore, the 24-h pHmetry is only indicated for patients who did not respond to empirical treatment with acid secretion inhibitors. $^{(10)}$

Endoscopy of the upper digestive tract remains an important exam in the evaluation of GERD. In some cases, it makes it possible to confirm the diagnosis, as well as to detect complications of the disease. Similarly, contrast-enhanced radiological examination of the esophagus, stomach and duodenum can detect alterations, although only in more advanced cases. However, these exams are incapable of objectively demonstrating the causal relationship between pathological acid reflux and respiratory symptoms. ${ }^{(10)}$

The empirical treatment used in the diagnosis of uncomplicated GERD is a good strategy for the evaluation of patients with GERD-induced asthma since it is relatively simple, inexpensive, and without the discomfort of invasive tests. ${ }^{(11)}$ Although there is no consensus regarding the objective measures (evaluating response, dosage used and duration of the test), various studies have demonstrated that such measures present high sensitivity and specificity. ${ }^{(11-13)} \ln$ a cost-effectiveness analysis of the available diagnostic strategies, ${ }^{(10)}$ it was concluded that the most cost-effective approach is empirical therapy with proton pump inhibitors (PPls), such as omeprazole at 20-40 mg/day for three months (followed by 24-h pHmetry for patients who do not respond to treatment).

Therefore, the initial step in the diagnosis of GERD-induced asthma should be empirical treatment to suppress acid, preferably with a PPI or, when appropriate, a PPI combined with $\mathrm{H}_{2}-$ receptor antagonists. ${ }^{(14)}$ Should symptoms persist, 24-h pHmetry should be performed in order to 
identify any failure in acid suppression or to consider another diagnosis. It should be borne in mind that warning symptoms such as dysphagia, odynophagia, anemia, weight loss or digestive hemorrhage indicate that the first course of action should be endoscopy of the upper digestive tract. ${ }^{(15)}$ One suggested approach is shown in Chart 2.

\section{Treatment}

In patients with uncomplicated GERD and presenting typical symptoms, the response to clinical treatment, as well as to surgical treatment, has been excellent. ${ }^{(16)}$ However, the therapeutic response in GERD patients presenting extra-esophageal symptoms is clearly less satisfactory.

A recent review compiled data from twelve studies, involving a total of 326 patients, in which the effects of acid-reduction therapy were used as an outcome measure of asthma control. ${ }^{(17)}$ The combined data revealed that asthma symptom severity was reduced in 69\% of the patients and that $62 \%$ of the patients were able to curtail their bronchodilator use without an increase in exacerbations. The authors concluded that the literature shows a clear benefit of clinical treatment in the control of asthma symptoms, with the possibility of reducing medication, although without satisfactory changes in spirometric parameters.

One study ${ }^{(18)}$ evaluated 30 patients with asthma and GERD with the objective of determining the dosage and duration of omeprazole treatment needed to reduce respiratory symptom severity. The patients initially received a three-month course at $20 \mathrm{mg} /$ day. From the fourth month onward, the dose was progressively increased until acid suppression, documented by 24-h pHmetry, occurred. In 73\% of the patients, respiratory symptom severity was reduced or peak expiratory flow increased. In 57\%,

Chart 2 - Suggested approach to empirical acid suppression therapy

Step Regimen

1. $\mathrm{PPl}$ in a single dose (before breakfast)

2. $\mathrm{PPl}$ in the morning and $\mathrm{H} 2 \mathrm{RA}$ at night (before meals)

3. PPl in the morning and at night (before meals)

4. PPI in the morning and at night (before meals) and $\mathrm{H}_{2}$ RA prior to sleeping

$\mathrm{PPI}=$ Proton pump inhibitor

$\mathrm{H}_{2} \mathrm{RA}=\mathrm{H}_{2}$ receptor antagonist there was a significant reduction in symptom severity by the end of the third month of treatment (prior to the increase in dosage). The mean omeprazole dose needed to obtain acid suppression was $27 \mathrm{mg} /$ day. Only $7 \%$ of the patients required doses higher than $40 \mathrm{mg} /$ day.

The inhibition of acid secretion, obtained through drug treatment, decreases the quantity of acid reflux. However, acid secretion inhibition, in isolation, does not prevent the reflux of other elements, such as food, bile and enzymes (pepsin, trypsin, etc.) into the esophagus and, in some cases, into the upper and lower airways. It is also known that gastric and pancreatic enzymes, together with bile, are the main causes of GERD complications. ${ }^{(19)}$ In addition, the high cost of the maintenance treatment with a PPI makes it unaffordable for a significant number of patients.

Since the causes of GERD are predominantly mechanical, the correction of the antireflux barrier through antireflux surgery controls two of the main etiological factors of GERD: the defective lower esophageal sphincter and the hiatal hernia.

The currently recommended surgery is laparoscopic fundoplication). It makes it possible to maintain the gastroesophageal junction in intraabdominal position and build a valve with the gastric fundus, safely re-establishing gastric cardia competence through the mechanical improvement of its function. Figure 1 shows the surgical sequence of Nissen fundoplication and its final aspect.

Some authors ${ }^{(20)}$ conducted an in-depth review of the literature analyzing the effects of the antireflux surgery on the symptom severity and the pulmonary function in patients with asthma and GERD. Of the 417 patients included in the analysis, a significant reduction in GERD symptom severity was obtained in $90 \%$ and in asthma symptom severity in $79 \%$. In addition, $88 \%$ curtailed their use of bronchodilators, and $27 \%$ presented improvement in their pulmonary function test results. The authors concluded that, although it has little effect on pulmonary function test results, antireflux surgery can significantly reduce GERD-related respiratory symptom severity and decrease the need for asthma control medications.

There have been few studies using appropriate methodology and directly comparing clinical and surgical treatments for the control of respiratory symptoms in patients with GERD. One study ${ }^{(21)}$ 
evaluated respiratory symptoms in patients with GERD initially treated with a PPl and later with antireflux surgery. The authors found that, after six months of PPI treatment, respiratory symptom severity decreased in only $14 \%$ of the patients, and none of the patients remained asymptomatic during this period. After laparoscopic fundoplication, respiratory symptom severity decreased in $86 \%$ of the patients, and $67 \%$ remained asymptomatic until the end of the study.

The results of these studies suggest that clinical treatment with a PPI should be the initial approach to GERD-related asthma. ${ }^{(22-23)}$ Surgical treatment is indicated for patients with GERD (documented by the 24-h pHmetry), especially for those who are under 50 years of age, who do not satisfactorily respond to clinical treatment, who suffer recurrence of symptoms within four weeks after the discontinuation of PPl therapy or who require continuous maintenance treatment with PPl.

\section{CHRONIC COUGH AND GERD}

Chronic cough, defined as persistent cough for a minimum period of eight weeks, is a frequent reason for patients to seek medical assistance. ${ }^{(24)}$ In the last three decades, GERD has been considered an important etiology of this symptom. Patients with chronic cough accompanied exclusively by GERD present a typical profile that includes being a nonsmoker, presenting a normal chest $\mathrm{X}$-ray and not currently using angiotensin-converting enzyme inhibitors. In up to $40 \%$ of cases, chronic cough is caused by GERD, postnasal drip or asthma. ${ }^{(25)}$ The cause-and-effect relationship between GERD and chronic cough is controversial for some authors, as is GERD-induced asthma. However, the principal evidence that GERD is the cause of chronic cough is based on the resolution of the symptoms after an efficacious antireflux treatment.

\section{Patogênese e diagnóstico}

Similarly to what occurs with asthma, two mechanisms have been proposed as an explanation to the association between GERD and chronic cough: the reflux of the acid gastric contents may reach the upper and lower airways causing cough; the reflux of the acid gastric contents can stimulate vagus nerve terminals in the esophagus, provoking a reflex cough.

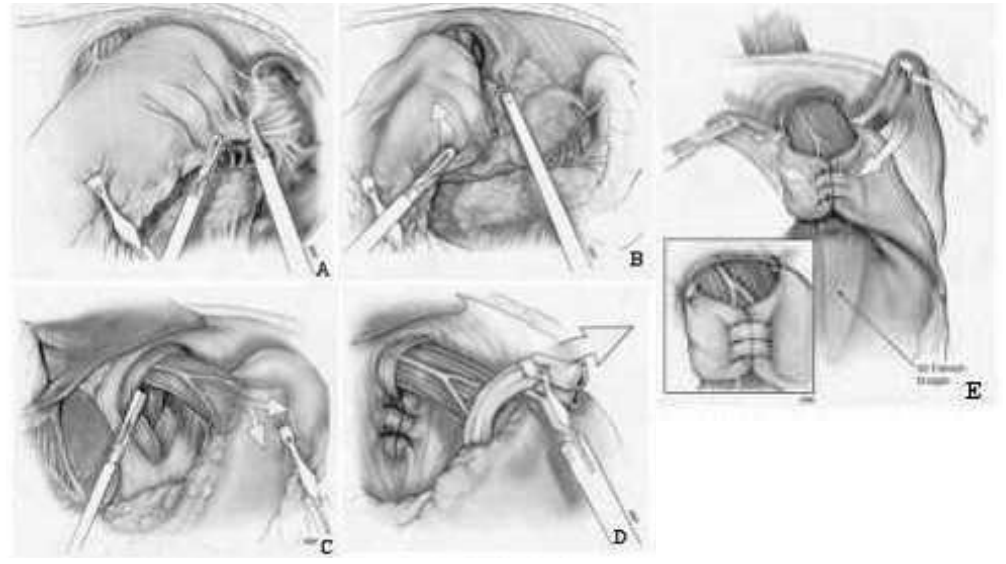

Figure 1- Surgical sequence for Nissen fundoplication. (A) Left crus approach; (B) incision in the phrenoesophageal membrane; (C) dissection of the right crus; (D) posterior crural closure; (E) involvement of the esophagus with the gastric fundus. Final aspect of Nissen fundoplication (detail). (Modified from Townsend: Sabiston Textbook of Surgery, 16th ed., 2001, W. B. Saunders Company)

According to some authors, ${ }^{(26)}$ who conducted a prospective study of the diagnostic value of taking a detailed patient history, clinical information about the cough, such as its characteristics, duration and time of day at which it occurs, is of little use in making the diagnosis.

It has been shown that neither endoscopy of the upper digestive tract, the gold standard for the diagnosis of GERD complications, nor contrastenhanced radiological examination of the esophagus, stomach and duodenum are capable of establishing a causal relationship between GERD and chronic cough. ${ }^{(27)}$

Uncontrolled studies have demonstrated an association between esophageal motility disorder and chronic cough. ${ }^{(28-29)}$ Therefore, esophageal manometry can be used in the diagnostic evaluation of cases that do not respond to clinical treatment with an antacid.

According to most published studies, 24-h pHmetry combined with a patient symptoms diary is a satisfactory diagnostic method of establishing a relationship between chronic cough and GERD. This method is especially useful because it can be correlated with the cough episodes reported by the patient in their symptoms diary. Nevertheless, the rate of false-negative results is high, and conventional measures of abnormal acid exposure may not be reported. ${ }^{(30)}$ In addition, non-acid reflux, which would not be detected by this diagnostic 
method, can induce cough in some patients,. ${ }^{(31)}$ Therefore, 24-h pHmetry is indicated only after the lack of response to empirical testing of acid suppression. Monitoring pharyngeal $\mathrm{pH}$ with a catheter placed two centimeters above the upper sphincter of the esophagus presents good accuracy in identifying the acid reflux that reaches the upper airways. However, the clinical utility of this exam has yet to be established. ${ }^{(32-33)}$

The therapeutic test of acid suppression has been proposed as a reasonable diagnostic strategy, and the results of various studies have validated this approach. ${ }^{(34)}$ A 12 -week controlled, randomized, double-blind study in patients diagnosed with GERD and presenting chronic cough compared the effect of $40 \mathrm{mg} /$ day of omeprazole to that of a placebo. ${ }^{(35)}$ Patients who responded favorably to the omeprazole achieved asymptomatic status between days 5 and 12 of treatment. Those authors proposed that, after other causes have been excluded, the use of omeprazole for 14 days accurately identifies patients with GERDrelated chronic cough. Therefore, this is the firstline diagnostic method for patients with chronic cough and suspected GERD.

A new diagnostic method, the monitoring of intraesophageal impedance, is being evaluated in prospective studies. This new method registers refluxed contents regardless of their $\mathrm{pH}$. It can identify reflux episodes with precision and, principally when used together with 24-h pHmetry, can differentiate acid reflux from alkaline reflux. ${ }^{(36)}$ This method allows the temporal association between reflux episodes and the respiratory symptom to be determined, as well as permitting patients who can benefit from the inhibition of acid secretion to be identified. ${ }^{(36)}$

\section{Treatment}

Although most investigative studies of the treatment of GERD-induced chronic cough have been uncontrolled, the literature shows that both clinical and surgical treatments are efficacious in reducing cough.

In one such uncontrolled study, a 4- to 6-week course of omeprazole at a dose of $40 \mathrm{mg}$, alone or combined with prokinetic agents (metoclopramide or cisapride) reduced GERD-related cough in 80\% of the patients studied. ${ }^{(37)}$

In one review of the literature, ${ }^{(38)}$ drug treatment of GERD-related chronic cough was evaluated in adults. In four of the seven studies reviewed, which involved a total of 68 patients, the response rate was from $97 \%$ to $100 \%$. However, in the one controlled study reviewed, which evaluated the effects of 40 mg of omeprazole twice a day, cough symptoms were resolved in only 35\% of the seventeen patients presenting abnormal 24-h pHmetry results (who had been evaluated for other causes of cough). ${ }^{(35)}$

The same authors, ${ }^{(38)}$ analyzing surgical treatment of GERD-related chronic cough in adults, demonstrated a 100\% response to treatment in two studies and a 56\% to $85 \%$ rate of favorable response in another four studies, all uncontrolled. In the most comprehensive study, which involved 42 patients, ${ }^{(39)}$ the authors demonstrated the effectiveness of antireflux surgery, combined with 24-h pHmetry and manometry in the postoperative period. The cough was resolved in 51\% of the patients and reduced in 31\%.

Various investigators have tried to identify preoperative predictors of good surgical outcomes. Some authors ${ }^{(40)}$ reviewed their experiences with laparoscopic Nissen fundoplication in 677 patients, $81 \%$ of whom had been allocated to a six-month follow-up evaluation involving 24-h pHmetry and esophageal manometry, as well as scoring for symptoms and quality of life. Heartburn was controlled in 93\%, and the cough was improved in $81 \%$ of the cases. Using multiple logistic regression analysis, the authors concluded that a favorable response to $\mathrm{PPls}$ in the preoperative period indicates a better surgical outcome.

The efficacy of clinical treatment with a PPI in reducing GERD-related cough has been demonstrated, making it the most highly recommended first-line approach. ${ }^{(25)}$ Nevertheless, a significant proportion of patients present recurrence of symptoms immediately after discontinuation of the treatment, therefore requiring continuous PPI therapy in moderate doses (from 40 to $60 \mathrm{mg}$ ). These patients, after confirmation of pathological acid reflux, are the ones who benefit the most from surgical treatment.

\section{IDIOPATHIC PULMONARY FIBROSIS AND GERD}

The association between idiopathic pulmonary fibrosis (IPF) and GERD has been suggested in some studies. Some authors ${ }^{(41)}$ used a contrast-enhanced 
radiological examination of the esophagus, stomach and duodenum to evaluate 48 patients with radiographic evidence of pulmonary fibrosis of unknown cause and demonstrated that, when compared to control individuals, they presented a higher incidence of hiatal hernia and pathological gastroesophageal reflux. Other authors ${ }^{(43)}$ used doublechannel monitoring of esophageal $\mathrm{pH}$ to evaluate seventeen patients with biopsy proven IPF. Sixteen of those patients presented distal or abnormal proximal esophageal acid exposure, and only 25\% of the patients with IPF reported typical GERD symptoms. The authors concluded that acid reflux can be a contributing factor in the pathogenesis of the IPF.

Although the association between GERD and IPF, as well as the physiopathological model, is convincing, a causal relationship has not been effectively proven. Antireflux treatment trials demonstrating the reduction or arrest of IPF progression have provided better evidence of the pathogenic role of GERD.

\section{OTHER PULMONARY DISEASES AND GERD}

Other diseases and pulmonary symptoms have been associated with GERD. In a comprehensive case-control study, ${ }^{(43)}$ esophagitis and esophageal stenosis were associated not only with asthma and pulmonary fibrosis but also with bronchiectasis, chronic obstructive pulmonary disease and pneumonia. It must be borne in mind that altered respiratory physiology predisposes to pathological acid reflux in some of these pathologies. ${ }^{(6)}$ Alternatively, GERD can cause pulmonary disease as a result of microaspiration or esophagobronchial reflex. However, it is possible that GERD and the abovementioned pulmonary diseases simply coexist with common risk factors, and further studies are necessary to demonstrate its causal relationship.

\section{LARYNGITIS AND GERD}

Although many otorhinolaryngologic diseases have been associated with GERD, the predominant manifestation is laryngitis. ${ }^{(19)}$ Based on various descriptions of laryngeal inflammatory alterations and on proposed lesion mechanisms, GERD-related laryngitis is known as posterior laryngitis, acid laryngitis, peptic laryngitis or, more recently, reflux laryngitis. Although the prevalence of reflux laryngitis is unknown, it is estimated that $4 \%$ to $10 \%$ of the patients who seek the assistance of an otorhinolaryngologist present GERD-related symptoms or findings. ${ }^{(44)}$

Similar to what has been found for other extraesophageal manifestations, it has been shown that a significant portion of patients with laryngeal manifestations of GERD, including reflux laryngitis, do not present the typical symptoms of GERD. ${ }^{(19)}$

\section{Pathogenesis and diagnosis}

Since the larynx is not continuous, is not mechanically cleaned and is not coated with saliva, gastric reflux remains in an undiluted form for a prolonged period of time, resulting in a greater probability of tissue lesion. The upper aerodigestive tract is exposed to acid reflux for a shorter length of time than is the esophagus. However, the probability of damage to the mucosa is probably higher. ${ }^{(45)}$

The symptoms of reflux laryngitis are nonspecific and cannot be differentiated from the symptoms of laryngitis with other causes. Hoarseness, the most common symptom, has been reported in more than $92 \%$ of the patients with reflux laryngitis. ${ }^{(45)}$ Other symptoms can include cough, throat clearing, odynophagia, altered voice, globus and dysphagia.

In patients with reflux laryngitis, the incidence of esophagitis is lower than in patients with typical GERD. Therefore, endoscopy of the upper digestive tract and contrast-enhanced radiological examination of the esophagus, stomach and duodenum are of little use in confirming the diagnosis. ${ }^{(19)}$

Laryngoscopy plays a fundamental role in the evaluation of chronic laryngitis. The classical abnormality described in reflux laryngitis is 'posterior laryngitis', which consists of the thickening of the mucosa accompanied by edema and erythema of the arytenoids.

Flexible endoscopy for the evaluation of deglutition, combined with a sensorial test, is a new technique that might become useful in the diagnosis of reflux laryngitis. The exam involves the use of laryngoscopy to estimate the response of the laryngeal adductor reflex to discrete pulses of air applied to the laryngopharyngeal mucosa.

The safest diagnostic test to confirm reflux laryngitis is documented resolution of the symptoms with the antireflux treatment. ${ }^{(46)}$ Some authors ${ }^{(47)}$ have reported that, using only precautions to prevent nocturnal reflux, reflux laryngitis was resolved at a 
rate of 51\%. With the addition of an $\mathrm{H} 2$ receptor antagonist, or omeprazole (20 mg/day at bedtime), the response rate increased to $96 \%$.

The documentation of pathological gastroesophageal reflux is appropriate in some patients, particularly in those with symptoms refractory to empirical treatment. Currently, doublechannel (esophageal and pharyngeal) outpatient monitoring of esophageal $\mathrm{pH}$ is considered the most sensitive means of diagnosing laryngopharyngeal reflux. $^{(31)}$

\section{Tratamento}

A favorable response to acid suppression in the treatment of patients with GERD-related laryngitis has been demonstrated in studies using appropriate methodology. Several uncontrolled studies also reported high laryngitis resolution rates after antireflux therapy. ${ }^{(48)}$

One study ${ }^{(49)}$ evaluated 45 patients with possibly GERD-related otorhinolaryngologic symptoms. The patients were treated for two months with $20 \mathrm{mg}$ of omeprazole twice a day or $30 \mathrm{mg}$ of lansoprazole twice a day. The authors found that, after two months, $47 \%$ of the patients presented improvement after two months, increasing to 64\% after four months. The authors concluded that empirical treatment with PPl twice a day for four months is efficacious in the identification and treatment of most patients with otorhinolaryngologic symptoms caused by GERD.

Unfortunately, six months after the discontinuation of any form of clinical therapy, approximately $80 \%$ of the patients suffer symptom recurrence. In addition, the bile and digestive enzymes (pepsin and trypsin) that are present in the refluxed contents (and which play a role in the pathogenesis of reflux laryngitis) continue to reflux even after aggressive clinical treatment with antacids. ${ }^{(48,50)}$

Uncontrolled data suggest that antireflux surgery is effective in most patients with reflux laryngitis. ${ }^{(48,51)}$ Studies evaluating the results of laparoscopic Nissen fundoplication have shown a response rate of over $70 \%$ among patients with GERD-related otorhinolaryngologic symptoms. ${ }^{\text {(52) }}$ The factors that are predictive of surgical success in these patients are good response to acid secretion inhibitors, $24-\mathrm{h}$ pHmetry demonstrating reflux in the hypopharynx, and preserved esophageal motility. ${ }^{(39,53)}$ Some authors ${ }^{(30)}$ have demonstrated that the probability of obtaining symptom relief through antireflux surgery is directly dependent on the preservation of esophageal motor skills. In addition, it has been proven that successful laparoscopic fundoplication is more cost-effective than is high-dose, long-term suppression therapy with a PPI. (54) Satisfactory surgical outcomes have also been demonstrated in studies involving pediatric patients with reflux laryngitis. One study ${ }^{(55)}$ evaluated 48 children who were refractory to treatment with high doses of an acid suppressive agent and whose symptoms had a significant impact on their daily activities. After the laparoscopic fundoplication, complete eradication of the symptoms was seen in $69 \%$ of the patients, and a significant improvement in quality of life was seen in over $90 \%$.

The first-line treatment of choice in patients with reflux laryngitis is the use of a $\mathrm{PPl}$ in moderate doses (e.g. omeprazole at $40 \mathrm{mg} /$ day) for a minimum of three months. In case of recurrence of symptoms after this period, the reflux should be confirmed through complementary exams (24$\mathrm{h}$ pHmetry) and the feasibility of performing laparoscopic fundoplication should be evaluated.

\section{OTHER DISEASES AND GERD}

In GERD-related otorhinolaryngologic diseases, laryngeal lesions (such as inflammation, edema, contact ulcer and granuloma formation) and laryngeal symptoms (such as hoarseness and globus) are the most widely studied processes. ${ }^{(45,56)}$ However, there is a long and growing list of allegedly GERDrelated otorhinolaryngologic diseases (Table 1), and there has been interest in the investigation of its association with various diseases, such as larynx cancer, sleep apnea, subglottic stenosis, vasomotor rhinitis, and laryngospasm.

For many years, some clinicians have suspected that GERD is a risk factor for laryngeal and pharyngeal cancer. However, the association has not been convincingly demonstrated. An evidence-based review $^{(57)}$ demonstrated that the causal association between GERD and laryngeal cancer is weak. This result can be explained by the difficulty in determining whether the association between neoplasia (laryngeal and pharyngeal) and GERD is simply related to shared risk factors such as smoking. However, in another study (a case-control 
study employing the Veterans Affairs Medical Center database), ${ }^{(58)}$ an association was demonstrated between GERD and neoplasia (laryngeal and pharyngeal). The association was apparently independent of age, gender, smoking and alcohol use. Recent studies demonstrate a delay in the progression of Barrett esophagus toward more advanced stages with surgical treatment of GERD. ${ }^{(59)}$ Since the carcinogenic effect of chronic exposure of the larynx to pathological gastroesophageal reflux can be compared to Barrett's esophagus, it is natural to infer that the surgical treatment of reflux will bring the same benefits for the prevention of pharyngeal and laryngeal neoplasia. However, further studies will have to be carried out in order to validate this type of benefit.

\section{CONCLUSIONS}

Although the extra-esophageal manifestations of GERD constitute heterogeneous disease groups, some general characterizations can be made.
The diagnosis can be particularly difficult due to the great prevalence of 'silent GERD' in the population. Traditional exams, such as endoscopy of the upper digestive tract and contrast-enhanced radiological examination of the esophagus, stomach and duodenum, can be useful in the diagnosis of GERD and are still important tools for the detection of esophageal complications. However, these exams might not confirm GERD, and, when they do, they do not establish a causal relationship between GERD and extra-esophageal symptoms. The most sensitive exam for the detection of GERD is 24-h pHmetry, which plays an important role in the evaluation of patients with extra-esophageal manifestations. Nevertheless, 24-h pHmetry might not confirm the causal relationship between GERD and the extraesophageal symptoms. Therefore, the empirical test with antireflux measures (behavioral and pharmacological) can be useful in establishing the diagnosis. Atypical manifestations generally require more aggressive and longer-term antisecretion therapy than do typical GERD symptoms. It is

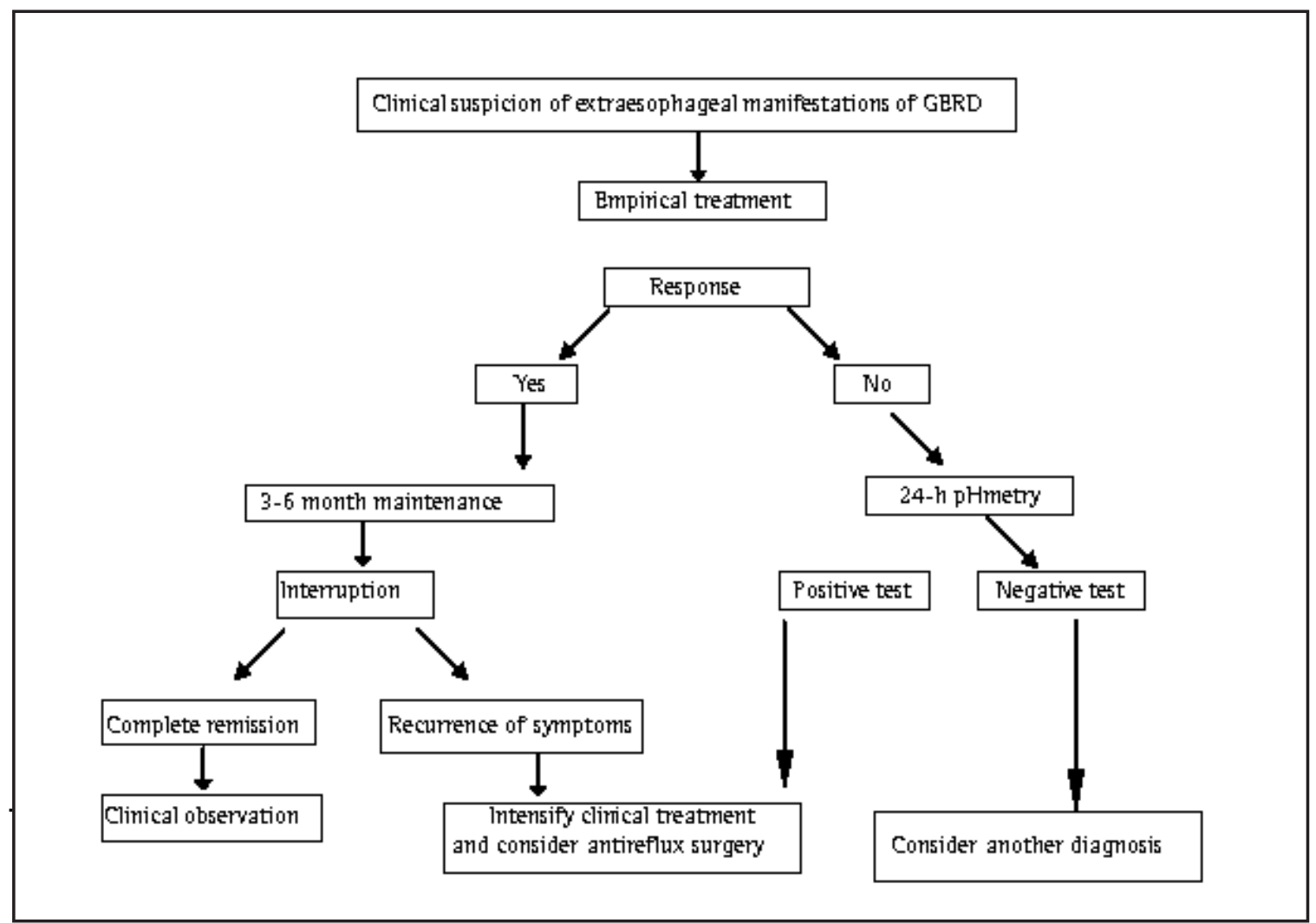

Figure 2 - Flow chart showing the suggested approach to the diagnosis and treatment of patients with extraesophageal manifestations of gastroesophageal reflux disease (GERD) ${ }^{(23)}$ 
noteworthy that the behavioral measures to avoid the exacerbation of pathological reflux are indicated for all patients suspected of having GERD and presenting atypical symptoms. The principal behavioral measures are as follows: elevating the head of the bed (by $15 \mathrm{~cm}$ ); exercising moderation regarding some types of food that have been correlated with symptoms (fat, citrus, coffee, alcoholic beverages, carbonated beverages, tomato-based products, chocolate, etc.); avoiding lying down within two hours after meals; avoiding large meals; avoiding wearing tight clothes; stopping smoking; and (in cases of obesity) losing weight. A suggested approach to the diagnosis and treatment of patients with extra-esophageal manifestations of GERD is shown in Figure 2.

\section{REFERENCES}

1. Locke GR 3rd, Talley NJ, Fett SL, Zinsmeister AR, Melton L 3rd. Prevalence and clinical spectrum of gastroesophageal reflux: a population-based study in Olmsted County, Minnesota. Gastroenterology. 1997;112(5):1148-56.

2. Vaezi MF, Schroeder PL, Richter JE. Reproducibility of proximal $\mathrm{pH}$ parameters in 24-hour ambulatory esophageal pH monitoring. Am J Gastroenterol. 1997;92(5):825-9.

3. Woolcock AJ, Peat JK. Evidence for the increase in asthma worldwide. Ciba Found Symp. 1997;206:12234; discussion 134-9, 157-9. Review.

4. Sontag SJ, O'Connel S, Khandelwal S, Miller T, Nemchausky B, Schnel TG, et al. Most asthmatics have gastroesophageal reflux with or without bronchodilator therapy. Gastroenterology. 1990;99(3):613-20. Comment in: Gastroenterology. 1990;99(3):613-20.

5. Sociedade Brasileira de Pneumologia e Tisiologia. Sociedade Brasileira de Pediatria. Sociedade Brasileira de Alergia e Imunologia; Sociedade Brasileira de Clinica Médica. 111 Consenso Brasileiro no Manejo da Asma. J Pneumol. 2002:28 Supl 1:S1-S28.

6. Mokhlesi B, Morris AL, Huang CF, Curcio AJ, Barrett TA, Kamp DW. Increased prevalence of gastroesophageal reflux symptoms in patients with COPD. Chest. $2001 ; 119(4): 1043-8$.

7. Crowell MD, Zayat EN, Lacy BE, Schettler-Duncan A, Liu MC. The effects of an inhaled beta- 2 adrenergic agonist on lower esophageal function: a dose-response study. Chest. 2001;120(4):1184-9.

8. Ekstrom TK, Tibbling L. Influence of theophylline on gastro-oesophageal reflux and asthma. Eur J Clin Pharmacol. 1988;35(4):353-6.

9. Andersen $\mathrm{Ll}$, Schmidt A, Bundgaard A. Pulmonary function and acid application in the esophagus. Chest. 1986;90(3):358-63.

10. O'Connor JF, Singer ME, Richter JE. The cost-effectiveness of strategies to assess gastroesophageal reflux as an exacerbating factor in asthma. Am J Gastroenterol. 1999;94(6):1472-80. Comment in: Am J Gastroenterol. 1999;94(12):3658.
11. Fass R, Ofman JJ, Gralnek IM, Johnson C, Camargo E, Sampliner RE, et al. Clinical and economic assessment of the omeprazole test with symptoms suggestive of gastroesophageal reflux disease. Arch Intern Med. 1999;159(18):2161-8.

12. Juul-Hansen P, Rydning A, Jacobsen CD, Hansen T. Highdose proton-pump inhibitors as a diagnostic test of gastro-oesophageal reflux disease in endoscopic- negative patients. Scand J Gastroenterol. 2001;36(8):806-10.

13. Bate CM, Riley SA, Chapman RW, Durnin AT, Taylor MD. Evaluation of omeprazole as a cost-effective diagnostic test for gastro-oesophageal reflux disease. Aliment Pharmacol Ther. 1999;13(1):59-66.

14. DeVault KR, Castell D0. Updated Guidelines for the diagnosis and treatment of gastroesophageal reflux disease. The Practice Parameters Committee of the American College of Gastroenterology. Am J Gastroenterol. 1999;94(6):1434-42.

15. Moraes-Filho J, Cecconello 1, Gama-Rodrigues J, Castro L, Henry MA, Meneghelli UG, et al. Brazilian Consensus Group. Brazilian consensus on gastroesophageal reflux disease; proposals for assessment classification,and management. Am J Gastroenterol. 2002;97(2):241-8.

16. Wong WM, Wong BC. Definition and diagnosis of gastroesophageal reflux disease. J Gastroenterol Hepatol. 2004;19 Suppl 3:S26-32.

17. Field SK, Sutherland LR. Does medical antireflux therapy improve asthma in asthmatics with gastroesophageal reflux?: a critical review of the literature. Chest. 1998;114(1):27583.

18. Harding SM, Richter JE, Guzzo MR, Schan CA, Alexander RW, Bradley LA. Asthma and gastroesophageal reflux: acid suppressive therapy improves asthma outcome. Am J Med. 1996;100(4):395-405.

19. Wong RK, Hanson DG, Waring PJ, Shaw G. ENT manifestations of gastroesophageal reflux. Am J Gastroenterol. 2000;95(8 Suppl):S15-22.

20. Field SK, Gelfand GA, McFadden SD. The effects of antireflux surgery on asthmatics with gastroesophageal reflux. Chest. 1999;116(3):766-74.

21. Wetscher GJ, Glaser K, Hinder RA, Perdikis G, Klingler P, Bammer $\mathrm{T}$, et al. Respiratory symptoms in patients with gastroesophageal reflux disease following medical therapy and following antireflux surgery. Am J Surg. 1997;174(6):639-42; discussion 642-3.

22. Wong WM, Fass R. Extraesophageal and atypical manifestations of GERD. J Gastroenterol Hepatol. 2004;19 Suppl 3:S33-43.

23. Bak YT. Management strategies for gastroesophageal reflux disease. J Gastroenterol Hepatol. 2004;19 Suppl 3:S49-53.

24. Palombini BC, Villanova CA, Araujo E, Gastal OL, Alt DC, Stolz DP, et al. A pathogenic triad in chronic cough : asthma, postnasal drip syndrome and gastroesophageal reflux disease. Chest. 1999;116(2):279-84. Comment in: Chest. 2000;117(4):1215-6; Chest. 2000;118(1):2789; Chest. 2000;118(1):279.

25. Fontana GA, Pistolesi M. Cough 3: chronic cough and gastro-oesophageal reflux. Thorax. 2003;58(12):1092-5. Comment in: Thorax. 2004;59(7):633; author reply 633-4.

26. Mello CJ, Irwin RS, Curley FJ. Predictive values of the character, timing, and complications of chronic cough in diagnosing its cause. Arch Intern Med. 1996;156(9):9971003. 
27. Irwin RS, French CL, Curley FJ, Zawacki JK, Bennett FM. Chronic cough due to gastroesophageal reflux. Clinical, diagnostic, and pathogenetic aspects. Chest. 1993;104(5): 1511-7. Comment in: Chest. 1993;104(5):1321-2.

28. DeMeester TR, Bonavina L, Lascone C, Courtney JV, Skinner DB. Chronic respiratory symptoms and occult gastrooesophageal reflux. A prospective clinical trial and results of surgical therapy. Ann Surg. 1990;211(3):337-45.

29. Knight RE, Wells JR, Parrish RS. Esophageal dysmotility as an important co-factor in extraesophageal manifestations of gastroesophageal reflux. Laryngoscope. 2000;110(9):1462-6.

30. Johnson WE, Hagen JA, DeMeester TR, Kauer WK, Ritter MP, Peters $\mathrm{JH}$, et al. Outcome of respiratory symptoms after antireflux surgery on patients with gastroesophageal reflux disease. Arch Surg. 1996;131(5):489-92.

31. Koufman JA, Aviv JE, Casiano RR, Shaw GY. Laryngopharyngeal reflux: position statement of the committee on speech, voice, and swallowing disorders of the American Academy of Otolaryngology Head and Neck Surgery. Otolaryngol Head Neck Surg. 2002;127(1):32-5.

32. Eubanks TR, Omelanczuk PE, Hillel A, Maronian N, Pope CE, Pellegrini CA. Pharyngeal $\mathrm{pH}$ measurements in patients with respiratory symptoms before and during proton pump inhibitor therapy. Am J Surg. 2001;181(5):466-70.

33. Eubanks TR, Omelanczuk PE, Maronian N, Hillel A, Pope CE 2nd, Pellegrini CA. Pharyngeal $\mathrm{pH}$ monitoring in 222 patients with suspected laryngeal reflux. J Gastrointest Surg. 2001;5(2):183-90; discussion 190-1.

34. Irwin RS, Boulet LP, Cloutier MM, Fuller R, Gold PM, Hoffstein $\mathrm{V}$, et al. Managing cough as a defense mechanism and as a symptom. A consensus panel report of the American College of Chest Physicians. Chest. 1998;114(2 Suppl Managing):133S181S. Comment in: Chest. 1999;115(2):602-3.

35. Ours TM, Kavuru MS, Schilz RJ; Richter JE. A prospective evaluation of esophageal testing and a double-blind, randomized study of omeprazole in a diagnostic and therapeutic algorithm for chronic cough. Am J Gastroenterol. 1999;94(11):3131-8. Comment in: Am J Gastroenterol. 1999;94(11):3095-8.

36. Sifrim D, Dupont L, Blondeau K, Zhang X, Tack J, Janssens J. Weakly acidic reflux in patients with chronic unexplained cough during 24 hour pressure, $\mathrm{pH}$, and impedance monitoring. Gut. 2005;54(4):449-54.

37. Poe RH, Kallay MC. Chronic cough and gastroesophageal reflux disease. Experience with specific therapy for diagnosis and treatment. Chest. 2003;123(3):679-84. Comment in: Chest. 2003;123(3):659-60.

38. Irwin RS, Richter JE. Gastroesophageal reflux and chronic cough. Am J Gastroenterol. 2000;95(8 Suppl):S9-14. Comment in: Am J Gastroenterol. 2001;96(2):598-9.

39. Allen CJ, Anvari M. Gastro-oesophageal reflux related cough and its response to laparoscopic fundoplication. Thorax. 1998;53(11):963-8.

40. Allen CJ, Anvari M. Preoperative symptom evaluation and esophageal acid infusion predict response to laparoscopic Nissen fundoplication in gastroesophageal reflux patients who present with cough. Surg Endosc. 2002;16(7):1037-41.

41. Mays EE, Dubois JJ, Hamilton GB. Pulmonary fibrosis associated with tracheobronchial aspiration. A study of the frequency of hiatal hernia and gastroesophageal reflux in interstitial pulmonary fibrosis of obscure etiology. Chest. 1976;69(4):512-5.
42. Tobin RW, Pope CE 2nd, Pellegrini CA, Emond MJ, Sillery J, Raghu G. Increased prevalence of gastroesophageal reflux in patients with idiopathic pulmonary fibrosis. Am J Respir Crit Care Med. 1998;158(6):1804-8.

43. El-Serag HB, Sonnenberg A. Comorbid occurrence of laryngeal or pulmonary disease with esophagitis in United States military veterans. Gastroenterology. 1997;113(3):755-60.

44. Tutuian R, Castell DO. Diagnosis of laryngopharyngeal reflux. Curr Opin Otolaryngol Head Neck Surg. 2004;12(3):174-9.

45. Toohill RJ, Kuhn JC. Role of refluxed acid in pathogenesis of laryngeal disorders. Am J Med. 1997;103(5A):100S-6S.

46. Richter JE. Extraesophageal presentations of gastroesophageal reflux disease: an overview. Am J Gastroenterol. 2000;95(8 Suppl):S1-3.

47. Hanson DG, Kamel PL, Kahrilas PL. Outcomes of antireflux therapy for the treatment of chronic laryngitis. Ann Otol Rhinol Laryngol. 1995;104(7):550-5.

48. Lindstrom DR, Wallace J, Loehrl TA, Meraati AL, Toohill RJ. Nissen fundoplication surgery for extraesophageal manifestations of gastroesophageal reflux (EER). Laryngoscope. 2002;112(10):1762-5.

49. Vaezi MF, Douglas MH, Ours TM. ENT manifestations of GERD: a large prospective study assessing treatment outcome and predictors of response. Gastroenterology. 2001;120 Suppl A: 118 .

50. Hinder RA, Branton SA, Floch NR. Surgical therapy for supraesophageal reflux complications of gastroesophageal reflux disease. Am J Med. 2000;108 Suppl 4a:178s-80s.

51. Waring JP, Lacayo L, Hunter J, Katz E, Suwak B. Chronic cough and hoarseness in patients with severe gastroesophageal reflux disease. Diagnosis and response to therapy. Dig Dis Sci. 1995;40(5):1093-7.

52. Westcott CJ, Hopkins MB, Bach K, Postma GN, Belafsky PC, Koufman JA. Fundoplication for laryngopharyngeal reflux disease. J Am Coll Surg. 2004;199(1):23-30. Comment in: J Am Coll Surg. 2004;199(5):837; author reply 838.

53. So JB, Zeitels SM, Rattner DW. Outcome of atypical symptoms attributed to gastroesophageal reflux treated by laparoscopic fundoplication. Surgery. 1998;124(1):28-32.

54. Hanson DG, Jiang JJ. Diagnosis and management of chronic laryngitis associated with reflux. Am J Med. 2000;108 Suppl 4a:112s-9s.

55. Mattioli G, Sacco 0, Gentilino V, Martino F, Pini Prato A, Castagnetti M, et al. Outcome of laparoscopic Nissen-Rossetti fundoplication in children with gastroesophageal reflux disease and supraesophageal symptoms. Surg Endosc. 2004;18(3):463-5.

56. Copper MP, Smit CF, Stanojcic LD, Devriese PP, Schouwenburg PF, Mathus-Vliegen LM. High incidence of laryngopharyngeal reflux in patients with head and neck cancer. Laryngoscope. 2000;110(6): 1007-11.

57. Weaver EM. Association between gastroesophageal reflux and sinusitis, otitis media, and laryngeal malignancy: a systematic review of the evidence. Am J Med. 2003;115 Suppl 3a:81s-9s.

58. El-Serag HB, Hepworth EJ, Lee P, Sonnenberg A. Gastroesophageal reflux disease is a risk factor for laryngeal and pharyngeal cancer. Am J Gastroenterol. 2001;96(7):2013-8.

59. Gurski RR, Peters JH, Hagen JA, DeMeester SR, Bremmer CG, Chandrasoma PT, et al. Barrett's esophagus can and does regress after antireflux surgery: a study of prevalence and predictive features. J Am Coll Surg. 2003;196(5):706-12; discussion 7123. Comment in: Gastroenterology. 2004;126(1):351-2; discussion 352-3; J Am Coll Surg. 2003;197(5):882-3. 